\title{
INOVAÇÕES METODOLÓGICAS NA EDUCAÇÃO SUPERIOR E A TRANSFORMAÇÃO DA PRÁTICA PEDAGÓGICA
}

\section{Methodological innovations in higher education and the transformation of the pedagogical practice}

Joana Paulin Romanowski*

Lílian Anna Wachowicz ${ }^{* *}$

\section{Resumo}

O texto é resultado de pesquisa realizada pelo Grupo de Pesquisa em Metodologia do Ensino e Avaliação da Aprendizagem na Educação Superior, do Programa de Pós-Graduação da PUCPR O estudo focaliza a prática profissional dos professores da PUCPR no contexto do Projeto Pedagógico e sua estruturação em Programas de Aprendizagem. Tem como objetivo avaliar as transformações dessa prática pedagógica sob a ótica dos professores e alunos desses programas. O estudo envolve oito programas de aprendizagem com relatos dos professores e avaliações dos estudantes, analisando interdependência teórico-prática entre metodologia do ensino e avaliação da aprendizagem, e interpretando, à luz das publicações mais significativas, os dados de pesquisa registrados. As conclusões apontam para a ocorrência de transformações da prática pedagógica com a inclusão dos alunos no processo de aprendizagem e a mudança nos procedimentos e habilidades de aprendizagem em decorrência de uma ação pedagógica que enfatiza as estratégias da aprendizagem que valoriza a relação teoria e prática. Palavras-chave: Educação superior, Prática pedagógica, Métodos inovadores, Avaliação.

* Professora do Programa de Pós-Graduação em Educação da PUCPR.

E-mail: joparo@rla01.pucpr.br

* Professora do Programa de Pós-Graduação em Educação da PUCPR.

Pontifícia Universidade Católica do Paraná - Mestrado em Educação, Rua Imaculada Conceição, 1155, Prado Velho, Curitiba - PR, CEP 80215-901.

E-mail: lil@rla01.pucpr.br 


\section{Abstract}

The text is a result of research conducted by the Teaching Methodology and Higher Education Leaming Evaluation Research Group of PUCPR' Postgraduation Program. The study focuses on the professional practice of PUCPR professors on the grounds of Pedagogical Project and its structuring in Leaming Programs. Its objective is to evaluate the transformations of this pedagogical practice under the scope of professors and alumni in these programs. The study involves eight leaming programs with reports from professors as well as students' evaluations, analyzing the theoretic-practical interdependence between teaching methodology and leaming evaluation, interpreting the registered data of research in the light of the most significant publications. Conclusions point to the occurrence of pedagogical practice transformations, with the inclusion of the students in the process of learning, and the change of leaming procedures and skills due to a pedagogical action thatemphasizes learning strategies which value the theoretic and practical relation. This text presents the latest results of research conducted by the Teaching Methodology and Higher Education Learning Evaluation Research Group of PUCPR' Post-graduation Program. This group had its origin from PUCPR Education professors, concerned with the pedagogical practice of some courses which had high failure rates, evasion (dropping out), and quitting, in graduation courses, especially in the Science and Technology Center, where rates were worrisome. The basic goal emphasized the development of higher education professors, considering the needs of change in this pedagogical practice. The analysis of this text synthesizes the results of investigations made in the year 2001, when the research project kept the definition of the topic of interest, under the scope of the transformation of the teaching practice, mainly focusing learning programs which are in progress in the institution.

Keywords: Superior education, Innovative methods, Evaluation.

Esse texto apresenta os resultados mais recentes das pesquisas realizadas pelo Grupo de Pesquisa em Metodologia do Ensino e Avaliação da Aprendizagem na Educação Superior, do Programa de Pós-Graduação da PUCPR. Este grupo teve origem da preocupação de professores da área de Educação da PUCPR, com a prática pedagógica de alguns cursos em que os elevados índices de reprovação, evasão e desistência de alunos nos cursos de graduação, especialmente no Centro de Ciências Exatas e de Tecnologia, manifestavam-se preocupantes. A finalidade básica enfatizava o desenvolvimento dos professores do ensino superior considerando as necessidades de mudança dessa prática pedagógica. Nas análises delineadas neste texto estão sintetizados os resultados das investigações realizadas durante o ano de 2001, em que o projeto de pesquisa manteve a definição do tema de interesse tendo em vista a transformação da prática docente focando, principalmente, os programas de aprendizagem que estão em andamento na instituição. 


\section{Programa de Aprendizagem}

Programa de aprendizagem é uma metodologia interdisciplinar de ensino, criada a partir de uma prática docente instituída na PUCPR, no ano letivo de 2000, e elaborada conceitualmente para expressar o trabalho de um ou mais professores de diferentes áreas de conhecimento, que se integram em ações pedagógicas planejadas em parceria, com a finalidade de orientar a aprendizagem dos estudantes. A metodologia tem, por finalidade, eliminar a fragmentação que se apresenta no currículo dos diversos cursos de graduação, na Educação Superior. Para isso, focaliza as ações pedagógicas, e não os conteúdos tomados em si mesmos, ou seja, como se realiza o trabalho do professor.

Nas publicações da área de Educação, as teorias de aprendizagem, que se apresentam com base neste princípio, agrupam-se na classificação de teorias da reestruturação ${ }^{1}$ e sua característica principal é a interestruturação sujeito e objeto na sua relação com o conhecimento (POZO, 1998). Quanto ao ensino, a metodologia de projetos parece ser a mais adequada. A dificuldade é que essa metodologia tem sido aplicada muito mais ao nível do Ensino Fundamental, sendo poucas as experiências com a Educação Superior.

Quanto aos conteúdos do ensino, é importante verificar o princípio teórico da transposição didática, apontado por Chevallard, a partir de suas experiências em Didática da Matemática. Segundo esse princípio, a transposição didática externa verifica-se quando os saberes acadêmicos (os saberes sábios, segundo o autor) são submetidos a uma recodificação, tornando-se saberes a serem ensinados; e a transposição interna, que se realiza no interior mesmo do sistema de ensino, bem depois da introdução oficial dos novos elementos no saber ensinado (CHEVALARD, 1991).

Quanto à avaliação, o princípio aceito pela legislação brasileira é o da avaliação cumulativa, na qual a melhor forma apresentada pelo estudante na sua aprendizagem incorpora e supera todas as outras formas anteriores. Esta melhor forma é a que revela a aprendizagem do aluno, portanto, é a que deve ser objeto de registro do resultado da aprendizagem. O problema é encontrar dispositivos regimentais que respeitem esse princípio, numa sistemática viciada em cálculos por média aritmética. Os aportes da psicologia cognitiva, apontados por Grégoire (2000), sobre avaliação diagnóstica dos distúrbios da aprendizagem em matemática, segundo seus estudos na Universidade Católica de Louvain, trazem essas ponderações para a avaliação da aprendizagem.

Entende-se que a abordagem cognitivista é a mais indicada, porém entendida segundo a dialética da ação educativa (WACHOWICZ, 2000). 


\section{Que Dizem os Professores}

Para o levantamento de dados, o grupo elegeu sua própria prática como fonte em dois momentos: primeiro, a descrição da prática desenvolvida durante as aulas; segundo, a referência aos dados obtidos por questionários respondidos pelos alunos.

Na primeira etapa, cada um dos pesquisadores ${ }^{2}$ realizou um relato de sua própria prática pedagógica. Nesse relato foram apresentadas as práticas docentes na sua dinâmica, nos cursos de Nutrição, Fonoaudiologia, Pedagogia, Licenciatura em Letras, que participam da implantação da nova proposta pedagógica que enfoca os Programas de Aprendizagem $^{3}$ (P. A.).

Como condição de trabalho, destaca-se que os P. A. são desenvolvidos por dois ou três professores articulando duas ou três disciplinas, considerando três momentos de fechamento parcial da avaliação (o regimento sistematiza a avaliação em três momentos para a emissão dos resultados parciais). A avaliação é contínua, de modo a oportunizar condições para o acompanhamento sistemático do desenvolvimento da aprendizagem dos alunos. A avaliação resultante é uma nota, geralmente o somatório de resultados de atividades. Ressalta-se, nesse contexto, a situação estressante para o professor vivenciar a avaliação cumulativa, com as inúmeras outras atividades que realiza e a difícil tarefa de administrar o tempo.

No fechamento dos resultados parciais, os alunos participam apresentando sugestões concretas para melhor rendimento do trabalho e da aprendizagem. Nesse caso, está em jogo a ação pedagógica direcionada para as estratégias de aprendizagem, como propõe Meirieu (1998). Destaca-se, por exemplo, a solicitação dos alunos para que a professora realizasse uma apresentação dos temas tratados, antes de discuti-los, ou seja, uma análise preliminar da abrangência dos estudos apontando as questões fundamentais. Nesse caso, os alunos consideram importante a mediação, feita pelo professor, entre eles e o conhecimento.

A proposta do programa de aprendizagem tem sido discutida com 0 conjunto de professores do curso, o que de fato constitui uma elaboração coletiva. É importante assinalar que os alunos recebem toda a programação, podendo sugerir propostas de conteúdos e ou atividades que são analisadas e incluídas.

Os professores consideram os programas bastante significativos, na medida em que estão relacionados à formação profissional necessária à futura atuação dos graduandos nas diferentes áreas profissionais. Entre as proposições e ações pedagógicas, realizadas pelos pesquisadores, destaca-se a preocupação com um conjunto de condições facilitadoras do processo de aprendizagem dos alunos da graduação, para que atuem com mais segurança em novas situações sociais. 
Os pressupostos didáticos referem-se a ensino associado à pesquisa indicados por André (2001), superação da fragmentação do conhecimento, participação dos estudantes na construção do conhecimento, teoria associada à prática, entre outros.

As experiências mais relevantes, realizadas nos programas de aprendizagem, direcionam-se para o processo ensino-aprendizagem pretendido que é a inovação das atividades de ensino, resultando em uma verdadeira práxis educativa articulada à realidade social. Isso cria oportunidades para que a relação teoria e prática aconteça nas experiências dos alunos. Julga-se como prioritário, nesta experiência, a busca de uma síntese que tenha o sentido da construção da totalidade - ponto de partida e de chegada do professor, o que estimula uma compreensão mais reflexiva e crítica da realidade. Os programas de aprendizagem procuram realizar práticas como eixos condutores de análise na qual a fundamentação teórica é suporte.

As atividades de aprendizagem desenvolvidas em sala de aula pressupõem a valorização de operações mentais superiores necessárias à aprendizagem significativa. Essas atividades são propostas tanto para proporcionar maior envolvimento dos alunos, como para propiciar atividades cognitivas que levem à produção de conhecimento, situações como planejar, organizar, construir e aplicar à realidade o tema proposto em aula. Insere a pesquisa na sistematização do estudo de tal modo que os alunos descrevam os procedimentos e destaquem a fundamentação teórica que subsidia a análise e a conclusão. Depois da elaboração da pesquisa, a comunicação é realizada coletivamente, apresentando os resultados e realizando o debate em grupo dos temas estudados.

Vale indicar alguns pontos das avaliações feitas pelos(as) alunos(as) em relação à primeira fase do trabalho teórico e prático: possibilidade de esclarecer dúvidas; muita criatividade, atividade dinâmica, em que o grupo incorporou inovações e aperfeiçoou seus referenciais com muita eficiência; promoção de troca de experiências com os colegas; ajuda mútua (cooperação), aprendizagem de novas técnicas; interesse de todos os participantes; interação entre os grupos; transposição da teoria para a prática; união do grupo em função dos objetivos da aula; compreensão de conteúdos importantes e relacionados com a profissão.

Pode-se destacar como aspecto positivo deste trabalho a aprendizagem significativa evidenciada construindo conhecimento e aproximando a aprendizagem às características do trabalho científico (pesquisa).

A sala de aula foi ampliada e aperfeiçoada para além do espaço físico. O que antes era feito mais pela aplicação de uma prova, na qual os alunos deveriam devolver as informações recebidas, é elaborado coletivamente com envolvimento intenso dos estudantes e aprofundamento das análises. 
As operações mentais, realizadas pelos alunos, incluem a compreensão geral dos temas tratados ao mesmo tempo em que a percepção das inter-relações entre as diferentes áreas do conhecimento é elaborada por eles com destaque para a complexidade dessas relações.

Salienta-se que os resultados apontam para uma metodologia que articula ensino e pesquisa, o que torna a aprendizagem uma experiência enriquecedora para alunos e professores, de tal modo que estes percebem a reação dos alunos como futuros profissionais e como pessoas. Além disso, os docentes transformam a própria prática como pesquisa. A metodologia de ensino ancora-se no paradigma de uma pedagogia diferenciada, compreendendo a diversidade das formas de ser e aprender. Várias estratégias que incitem à reflexão crítica, ao raciocínio clínico, à análise e à síntese serão desenvolvidas em sala de aula. O número reduzido de aulas expositivas, a discussão coletiva de leituras interpretativas realizadas individual e coletivamente, a realização de seminários, de resolução de situações problemas, a produção de textos científicos coletivos ou individuais favorecerá o posicionamento da aluna e do aluno como parceiros do professor no processo ensino aprendizagem. Enquanto tal, as atividades de estudo poderão sofrer modificações a partir das negociações que se estabelecerão entre esses parceiros.

\section{0 que Dizem os Alunos}

As categorias abordadas nas questões propostas para os alunos participantes, nesta investigação, envolveram condições para desenvolver aprendizagens significativas como tempo, número de alunos na classe, materiais didáticos utilizados durante as aulas, no caso os textos quanto à sua quantidade e atualidade, procedimentos e processos de aprendizagem, processo de avaliação como condição de aprendizagens efetivas, relação entre professores e alunos e interação dos conteúdos. As proposições das questões foram feitas por meio de perguntas abertas e fechadas, sendo estas apresentadas com três ou mais alternativas.

As respostas obtidas quanto às condições de realização do programa de aprendizagem indicam que o tempo é adequado para a realização das atividades e que o número é suficiente, favorecendo compreender os conceitos básicos, perceber a aplicação na prática profissional, ampliar o campo de conhecimentos, provocar a interação entre os alunos e promover o crescimento individual como pessoa. Entre as atividades mais significativas foram citados debates, aulas expositivas "muito importantes", resumos de cada aula, palestras, elaboração de textos, pesquisa, discussão, estágios de observação, trabalhos em grupo, análise de filmes, realização de seminários, sistematização dos conceitos básicos, síntese e esquema de textos, análises de levanta- 
mento de dados da realidade, visitas à escola e oficinas, revelando a diversidade de estratégias de aprendizagem efetivadas nos programas de aprendizagem.

Cabe enfatizar que os alunos reportaram-se aos aspectos comunicativos dos materiais empregados nas aulas salientando que são acessíveis e favorecendo a compreensão dos temas de estudo. Houve comentários como "no princípio, foi muito difícil a linguagem". Segundo alguns alunos, antes da exposição pela professora, é mais difícil compreender os conceitos, pois exigem conhecimentos prévios, posteriormente acontece a compreensão. Para os alunos, a criticidade está presente nos debates e permite o desvelamento e a compreensão de questões antes não percebidas, dizem eles: "aprendemos a ver o outro lado da moeda".

As atividades em cada programa foram consideradas adequadas, mas houve críticas quanto à articulação no curso, pois para alguns alunos as atividades não estão articuladas umas com as outras.

Entre as dificuldades citadas pelos alunos uma delas refere-se à organização dos estágios, pois em alguns cursos são centralizados numa determinada fase do programa e não distribuídos ao longo do semestre e do curso. $\mathrm{O}$ questionamento realizado durante o estágio nem sempre permite uma articulação com as situações da atuação profissional. Além disso, dizem uns alunos, falta cooperação entre os colegas, visto que alguns escondem informações durante os seminários, o que acaba gerando falta de interação entre eles e destes com os programas do curso.

Evidencia-se na fala dos alunos um envolvimento com a aprendizagem e a formação, afirma um respondente "Tenho uma crítica positiva sobre a LDB: as professoras debateram bastante 0 assunto onde os estudantes querendo ou não aprenderam algo"; alguns sugeriram mais aulas teóricas, pois não têm tempo para estudar, muitos alunos trabalham. Esta dificuldade é percebida por outros que sugerem: "A turma precisa ler mais, se inteirar e participar melhor". Igualmente, consideram importante quando as atividades permitem articular com situações práticas.

Quanto à integração entre as áreas do programa de aprendizagem, a maioria declarou que ocorreu a integração entre as áreas do conhecimento do programa e muitos declararam que houve a integração com os demais programas de aprendizagem. É interessante que há declarações que demonstram que os alunos conseguem perceber a interação entre áreas de conhecimento entre um e outro semestre: "Quando entendi a palestra do Prof. E., entendi melhor a aula do Prof. C..., ministradas no ano anterior". Mas há críticas: "Não consegui assimilar D... com a Prof. F...".

Sobre o relacionamento com os professores, a maioria declarou que é interativo, poucos indicaram que é indiferente ou conflituoso. Há comentários como: "Ótimo, é bom contar com você". "No começo houve 
conflito, agora não mais".E, "a professora é aberta a críticas, principalmente quanto à busca de novos recursos para o programa de aprendizagem". Quando considerado conflituoso os motivos apontados, reportam-se: "não sabe ouvir"; "os professores não entendem a proposta"; "professores que não se atualizam". Afirmam, também, que "com alguns professores não se tem diálogo, até mesmo para perguntar sobre a matéria".

O relacionamento com as colegas foi declarado semelhante ao dos professores. A maioria afirma ser ele interativo, alguns são conflituosos, ou indiferentes. As declarações expressam que "a turma entra em conflitos pessoais". Sabem que existem problemas; o grupo às vezes está desunido e a falta de interesse de alguns alunos acaba em conflitos com os que querem realmente aproveitar os estudos.

Os dados obtidos, quanto ao processo de aprendizagem, indicam que ocorre uma aprendizagem compreensiva, favorecendo elaboração de conceitos novos e inovadores, possibilitando adquirir novas habilidades de pensamento, principalmente a crítica para favorecer análises entre a teoria e a prática. Em menor número foram citadas as seguintes: a dialética que permite perceber possibilidades de intervenção na realidade; a técnica para aprender novos modos de proceder no trabalho; a criativa por vivenciar outros processos de elaboração do conhecimento; a seletiva, favorecendo procedimentos de seleção e organização da informação; a reflexiva sobre situações vivenciadas anteriormente revendo suas posições; a interativa por utilizar diferentes modos de descoberta e organização do conhecimento e a diversificada, pois ocorreram diferentes oportunidades de elaboração do conhecimento.

Sobre o processo de avaliação, muitos respondentes declararam que os instrumentos e procedimentos produziram maior aprendizagem, que também tensão e insegurança. No entanto, reconhecem que foram adequados. A aprovação no P. A. é decorrente de rendimento acima da média no conjunto das áreas de conhecimento, sendo poucos aprovados porque obtém rendimento superior em uma das áreas. As observações exemplares desses reportam-se a: "As médias são boas, mas não obtive a compreensão de todos os temas"; "Atribuo meu rendimento ao meu interesse"; "Devido a problemas familiares, não pude ter o rendimento que gostaria"; "Dificuldades pessoais interferiram". Entre os procedimentos mais significativos foram indicados os seminários, as pesquisas, os relatos de observações, os trabalhos em grupo, a avaliação constante em sala, relatórios e apresentação dos estágios, elaboração de artigos individuais, análise crítica das apresentações, elaboração de propostas. A percepção sobre a dificuldade de realização da avaliação se manifesta nos seguintes comentários: "Os seminários são bons para a aprendizagem, mas difíceis de serem 
avaliados"; "Os debates são importantes para a aprendizagem, mas a avaliação feita durante o debate não foi boa". Os alunos valorizam uma nova postura em relação à avaliação quando declaram: "Aprovo a idéia de não ser feita média para chegar à nota final"; "A forma cumulativa é muito interessante"; "Um instrumento significativo é a síntese"; "As avaliações de Didática são bastante interessantes, porque se aprende mais".

Quando as avaliações produzem medo e insegurança são atribuídas à: medo de falar em público em seminários; avaliação sem consulta, elaboração de texto coletivo, sínteses elaboradas individualmente, prova individual, muitos professores se preocupam só com a nota, avaliações que são passadas e cobradas sem que o professor tenha trabalhado o conceito, falta de clareza de quais atividades irão compor a nota. Um respondente comentou que a repetição do mesmo tipo de aula e de avaliação torna cansativo, ficando a matéria sem sentido. Sobre a avaliação, observou-se maior número de contradição nas respostas, pois o que gera medo e insegurança para alguns é situação favorável para outros.

Uma última proposição do questionário foi a tribuna livre, em que cada um dos alunos poderia realizar sua apreciação ao P.A. Muitos alunos se reportaram aos diferentes programas manifestando livremente sua opinião. Algumas declarações dos alunos: "Minha única dúvida é a respeito do ensino com pesquisa. Será que tudo o que nós pesquisamos é correto? Não tendo aulas expositivas, ficamos com várias dúvidas. Outra coisa é quanto à avaliação em cima de uma discussão. Como avaliar?"; "Com certeza esse P. A. contribuiu muito para ampliar meus conhecimentos"; "Percebi que realmente houve integração entre os programas de aprendizagem"; "As pesquisas que fazemos são significativas, mas sem as aulas expositivas alguns assuntos ficam vagos"; "As aulas são claras porque têm exemplos da realidade"; "Professores acessíveis favorecem a aprendizagem"; "Adorei, pois houve interdisciplinaridade dando assim grande oportunidade para aprender mais e mais"; "Fiquei realmente satisfeita com a inovação. O que considerei negativo foi o excesso de conteúdos, pois com uma informação às vezes alguma coisa passa despercebida, mas com relação às aulas estou satisfeita".

\section{A Prática Docente: Espaço de Transformação}

As reflexões realizadas pelos professores revelam que a metodologia de ensino utilizada busca superar os processos tradicionais de ensino. Mesmo que ocorra a exposição do professor ela busca explicitar e constituir o significado do conhecimento e não sua reprodução. As atividades propostas pelos professores procuram estabelecer a relação teoria e prática, bem 
como a análise crítica da realidade. A problematização e o estudo de caso são os procedimentos de ensino aprendizagem mais utilizados. Os estudos e debates coletivos estão incorporados no cotidiano da sala de aula. É possível afirmar que está ocorrendo a mudança do ensino.

Para os alunos, o Programa de Aprendizagem é um processo que apresenta uma nova abordagem para ensinar e aprender, pois a maioria deles afirmou que está ocorrendo uma interação entre as áreas de conhecimento e que os textos exigem um conhecimento anterior. Foi evidenciado que os processos de elaboração do conhecimento superam a reprodução para uma aprendizagem mais compreensiva, crítica e inovadora.

A indicação de que as turmas pudessem se constituir com menor número de alunos aparece nas turmas com mais de 50 alunos. As turmas com menos de 25 alunos gostariam que as classes tivessem mais alunos. Qual seria, portanto, o número adequado de alunos para a composição das turmas de ensino superior?

Salienta-se que professores e alunos concordaram que o P.A. foi inovador e contribuiu para um crescimento não somente profissional, mas também pessoal e, o que é mais importante, realizaram conexões com outros programas, ou mesmo dentro do próprio programa, puderam comparar e criticar as diversas situações vividas. Talvez signifique que novos rumos da Didática, no ensino superior, estão sendo consolidados.

A inovação pedagógica deste trabalho pode ser percebida no processo que está em desenvolvimento, talvez não seja o conteúdo dos P.A. nem os procedimentos docentes, mas as atitudes que os alunos formam no trabalho com o conhecimento e que no seu conjunto constituem a formação da competência. (RIOS, 2001).

A possibilidade de uma nova leitura, realizada pelos alunos nesse processo, leva a uma percepção da mudança da postura do aluno quanto à finalidade da aprendizagem que supera a visão cartorial e bancária. (FREIRE, 1997).

Na continuidade desta investigação, apresenta-se um novo desafio: o aprofundamento na direção da aprendizagem dos alunos do ensino superior como um dos indicativos de pesquisa para o grupo.

\section{Notas}

1 Juan Ignacio Pozo apresenta nessa categoria as teorias da Gestalt, ou aprendizagem por insight, a teoria da equilibração de Piaget, a teoria da aprendizagem de Vygotsky e a teoria da aprendizagem significativa, de Ausubel. 
2 Participam do Grupo de Pesquisa Lílian Anna Wachowicz (líder), Valéria Ramos Leitão (vicelíder), Ana Cristina Miguez Ribeiro, Joana Paulin Romanowski, Lúcia Raquel Miranda Passerino, Regiane Bergamo, Regina Brenner Kasai e Vera Maria Paz Brito Malucelli. Os depoimentos indicados estão registrados no Relatório do Grupo de pesquisa Metodologia do Ensino e Avaliação da Aprendizagem na Educação Superior, Linha de Pesquisa: Teoria e Prática Pedagógica da Educação Superior, PONTIFÍCIA UNIVERSIDADE CATÓLICA DO PARANÁ, 2002.

3 Aspectos Biopsicológicos da Aprendizagem, Gestão Integrada do Processo Pedagógico, Organização e Gestão da Escola, Aspectos Filosóficos e Processos Didáticos da Aprendizagem, Avaliação e Medidas Educacionais, desenvolvidos no curso de Pedagogia; Identificação da Prática Profissional, no curso de Nutrição, Fundamentos Históricos, Sociológicos e Psicológicos dos Paradigmas Educacionais, nos cursos de Licenciatura; Fonoaudiologia em Voz, no curso de Fonoaudiologia.

\section{Referências}

ANDRÉ, M. (0rg.). O papel da pesquisa na formação e prática dos professores. Campinas: Papirus, 2001.

BEHRENS, M. Projetos de aprendizagem colaborativa num paradigma emergente. In: BEHRENS, M. MORAN, J. M.; MASETTO, M. T. Novas tecnologias e mediação pedagógica. 5. ed. Campinas: Papirus, 2003.

CAPRA, F. A teia da vida: uma nova compreensão científica dos sistemas vivos. São Paulo, SP: Cultix, 1996.

CARDOSO, C. A canção da inteireza: uma nova visão holística da educação. São Paulo, SP: Summus, 1995.

CHEVALLARD,Y. La Transposición Didáctica: del saber sabio al saber enseñado. Buenos Aires: Aique, 1991.

DEMO, P. Pesquisa e construção do conhecimento. Metodologia científica no caminho de Habermas. Rio de Janeiro, RJ: Tempo Brasileiro, 1994.

FREIRE, P. Pedagogia da autonomia: saberes necessários à prática educativa. Rio de Janeiro, RJ: Paz e Terra. 1997.

GRÉGOIRE, J. Avaliando as aprendizagens: os aportes da psicologia cognitiva. Porto Alegre: Artes Médicas, 2000.

JOLIBERT, J. et al. Transformar la formación docente inicial. Santiago: Antártica, 1996.

MEIRIEU, Philippe. Aprender... sim, mascomo. Porto Alegre: Artes Médicas, 1998. 
RIOS, T. Compreender e ensinar: por uma docência da melhor qualidade. São Paulo, SP: Cortez, 2001.

POZO, J. I. Teorias cognitivas da aprendizagem. Porto Alegre: Artes Médicas, 1998.

WACHOWICZ, L. A. A dialética da avaliação da aprendizagem, na pedagogia diferenciada. In: CASTANHO, M.E. e CASTANHO, S. (Orgs.). o que há de novo na Educação Superior. Campinas: Papirus, 2000. p. 95 - 131.

Recebido em 05/03/2003 Aprovado em 09/07/2003 